\title{
Percutaneous pleural drainage in patients taking clopidogrel: real danger or phantom fear?
}

\author{
Katherine Linder ${ }^{1}$, Oleg Epelbaum ${ }^{2}$ \\ ${ }^{1}$ Department of Internal Medicine, ${ }^{2}$ Division of Pulmonary, Critical Care, and Sleep Medicine, Westchester Medical Center, Valhalla, NY, USA \\ Contributions: (I) Conception and design: All authors; (II) Administrative support: None; (III) Provision of study materials or patients: None; (IV) \\ Collection and assembly of data: All authors; (V) Data analysis and interpretation: None; (VI) Manuscript writing: All authors; (VII) Final approval of \\ manuscript: All authors. \\ Correspondence to: Oleg Epelbaum, MD. Division of Pulmonary, Critical Care, and Sleep Medicine, Westchester Medical Center, 100 Woods Road, \\ Valhalla, NY 10595, USA. Email: oleg.epelbaum@wmchealth.org.
}

\begin{abstract}
Despite being categorized as a procedure associated with a low risk of iatrogenic hemorrhage, percutaneous pleural drainage in patients taking the ubiquitous antiplatelet agent clopidogrel is still commonly perceived as a risky proposition. There is mounting evidence, however, in support of the safety of percutaneous needle procedures in persons receiving this medication. Establishing that these pleural interventions can be performed safely without clopidogrel interruption would be of great clinical significance, especially in those taking it for recent cardiac stenting and therefore in danger of stent thrombosis should antiplatelet therapy (APT) be withheld. The purpose of the present review is to summarize the available data from published studies and series of thoracentesis and chest tube insertion in patients exposed to clopidogrel. Also incorporated into this review are relevant investigations from the thoracic surgery and interventional radiology experience, which contribute indirect evidence and help shape the context for interpreting the safety data reported in the pleural literature. At the end, an attempt is made to synthesize the current knowledge on this topic into conclusions for guiding practice.
\end{abstract}

Keywords: Thoracentesis; chest tube; pleural drainage; clopidogrel; hemothorax

Submitted Apr 11, 2018. Accepted for publication Apr 19, 2018.

doi: $10.21037 /$ jtd.2018.04.161

View this article at: http://dx.doi.org/10.21037/jtd.2018.04.161

\section{Introduction}

The hesitation on the part of many in the interventional pulmonology community to perform percutaneous pleural drainage in patients receiving clopidogrel is an extrapolation of traditional surgical concerns about operating on patients in the setting of profound platelet inhibition. When it comes to hemostasis, the surgeon's situation is both comparatively advantageous and disadvantageous. On the one hand, surgery is a more radical intervention than a percutaneous procedure with the possibility of major vascular injury. On the other hand, the surgeon has better access to the site of iatrogenic bleeding and has the technical ability to achieve hemostasis by means of immediate operative repair. Solving this problem by suspending clopidogrel therapy constitutes a potentially significant safety compromise, especially in patients who have undergone recent coronary stenting. Moreover, pleural drainage is often urgent enough to preclude the possibility of delaying it until the effect of clopidogrel dissipates. In the current era of routine ultrasound (US) guidance and shift to smaller tubes, the possibility that percutaneous pleural drainage can be performed safely while continuing clopidogrel is being raised increasingly in interventional pulmonology circles (1). In this review, we familiarize the reader with the pharmacology of clopidogrel, review the risks posed by its periprocedural discontinuation, discuss potentially applicable data from the thoracic surgery and interventional radiology literature, and summarize the available studies of percutaneous pleural drainage in those taking clopidogrel. 


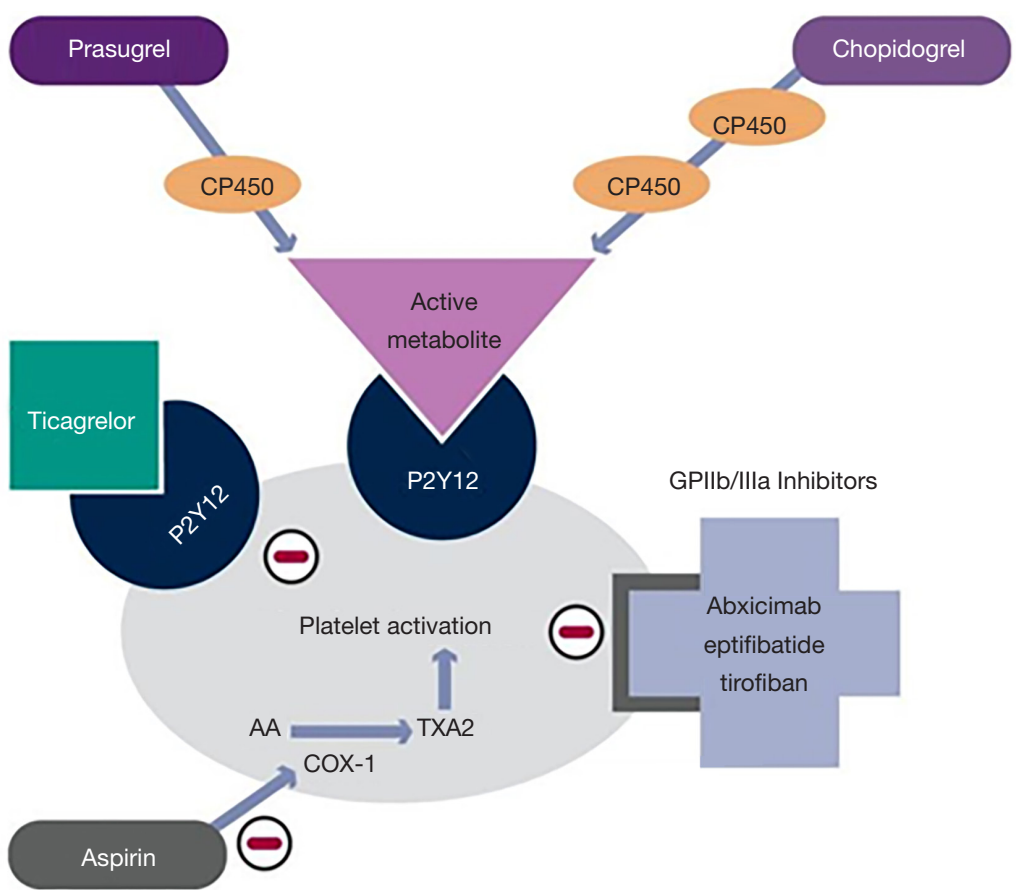

Figure 1 Graphical representation of the mechanism of action of the clinically important thienopyridines, clopidogrel and prasugrel, as well as of other antiplatelet agents. Of note, although it is also an antagonist of the P2Y12 receptor, ticagrelor does not belong to the thienopyridine family. AA, arachidonic acid; COX-1, cyclooxygenase-1; CP450, cytochrome P450; P2Y12, purinergic receptor P2Y; GPIIb/IIIa, glycoprotein IIb/IIIa; TXA2, thromboxane A2. Adapted from Kandan et al. (25) [C 2010 Radcliffe Cardiology. Figure reproduced with permission].

Finally, we attempt to draw conclusions for clinical practice based on the totality of current evidence.

\section{Background of thienopyridines}

Platelet plugs serve as the initial mechanism of hemostatic repair of vascular endothelial injury and are eventually reinforced by a fibrin mesh to form a mature clot. For therapeutic inhibition of clotting, platelet receptors regulating activation and aggregation, such as the adenosine diphosphate (ADP) receptor P2Y12, have long been attractive targets (2). The thienopyridines were the first class of medications developed to antagonize the ADP P2Y12 receptor. Members of this drug class, which includes ticlopidine, clopidogrel, and prasugrel, exert their antiplatelet effect by irreversibly blocking the P2Y12 receptor from interacting with its ligand ADP (3). This interrupts the cascade of platelet activation and aggregation that ultimately leads to clot formation (3-6). The inhibitory effect of these medications lasts for the lifetime of the platelet (7).

All thienopyridines are oral prodrugs that require conversion to active metabolites $(3,8)$. Ticlopidine and clopidogrel require two conversion steps to generate their active metabolites, which results in a delayed onset of action $(9,10)$. Once cumulative dosing reaches a therapeutic level, however, recovery of platelet function after drug withdrawal occurs slowly $(3,11)$. Prasugrel has a more rapid onset of action and requires only one step to generate its active metabolites (3). The clinical use of the firstgeneration agent ticlopidine has been limited by bone marrow toxicity (12). Third-generation prasugrel has the most potent inhibitory effect, but this advantage is offset by its tendency to increase bleeding events (13-15). As a result, clopidogrel-the second-generation thienopyridineremains the most widely used option in this drug class. It suffers from great variability of the antiplatelet response due in part to different rates of absorption and to polymorphisms of the regulatory gene CYP2C19 involved in the generation of its active metabolites $(3,13,16)$. Clopidogrel has a half-life of approximately 8 hours with platelet inhibition starting at 48 hours with daily oral dosing of 50-100mg. Steady state levels are reached after 4-7 days, and the antiplatelet effect lingers for $7-10$ days $(17,18)$. 
Despite these shortcomings, clopidogrel is well-established therapy for patients with cerebrovascular disease, peripheral vascular disease, acute coronary syndromes, and for those undergoing percutaneous coronary intervention (PCI), particularly with stent placement (14,19-24). Figure 1 graphically illustrates the mechanism of action of the thienopyridines as well as other commonly used antiplatelet agents.

\section{Cardiac risks of clopidogrel discontinuation}

Patients with recently placed coronary stents on APT that includes clopidogrel pose a clinical dilemma if non-cardiac surgery is required. On one side are fears about increased bleeding risk and failure of intraoperative hemostasis. On the other is this population's predisposition to adverse perioperative cardiac events if APT is discontinued prematurely $(26,27)$. In patients with coronary stents, premature discontinuation of clopidogrel is associated with an increased risk for thrombosis $(13,28,29)$, myocardial infarction (30), and an increase in overall mortality $(29,31,32)$. This is particularly true for those receiving drug-eluting stents (DES) because several studies have reported a $29 \%$ or greater increase in the risk of coronary thrombosis if clopidogrel is withdrawn prematurely $(17,29,33)$. In a prospective multi-center, observational cohort of 1,134 patients with coronary stents, the strongest independent risk factor for stent thrombosis within 30 days of PCI was the absence of clopidogrel therapy. There was also a strong association with stent thrombosis if clopidogrel was discontinued between 30 days and 6 months, and even beyond 6 months of the index PCI (34). A systematic review and meta-analysis found that after the recommended minimum 12-month period of dual APT for DES, there is still an increased risk for death and coronary events associated with stopping these medications (35). Data suggest that the most significant independent risk factor for perioperative coronary stent thrombosis and myocardial infarction is the discontinuation of oral APT for more than 5 days prior to non-cardiac surgery $(13,36,37)$.

\section{Thoracic surgery and clopidogrel}

Historically, thoracic surgeons have been reluctant to operate in the chest of patients obligated to take clopidogrel for recent cardiac stenting. This poses a problem when the surgery is urgent, such as in the case of empyema, and even when it is time-sensitive, such as resection of lung cancer.
Cerfolio et al. were the first to publish their experience of performing thoracic surgery without interruption of APT, which could have been clopidogrel alone or clopidogrel plus aspirin (17). None of the 27 patients whom they took to the operating room (OR) on APT for primary surgery required blood transfusions or re-operation for bleeding. However, both patients taking aspirin and clopidogrel who were undergoing repeat thoracic surgery required a return to the OR for bleeding. Additionally, the patients receiving APT at the time of surgery had a significantly greater chest tube output during the first 2 post-operative days. Of note, this series did not include any operations in the pleural space. Ceppa et al. subsequently analyzed 54 patients who underwent mostly thoracoscopic lung cancer resection during treatment with clopidogrel and compared them to 108 historical, propensity score matched controls not treated with clopidogrel perioperatively (38). Only one patient, from the control group, required reoperation for bleeding. There was no difference between the groups in the need for blood transfusion or prolonged chest tube drainage. Yu et al. reported a series of 58 patients who underwent lung resectional surgery on APT; half were taking clopidogrel $(n=18)$ or clopidogrel plus aspirin $(n=11)(39)$. Three patients experienced post-operative bleeding, all were recipients of dual therapy, but none required re-operation. Four of the 11 dual therapy patients received blood transfusions postoperatively, and all four had extensive pleural adhesions encountered at surgery. The dual therapy patients had significantly greater chest tube output than those receiving other forms of APT. Within the limitations of available data, initial resectional thoracic surgery on APT appears to be safe, with the caveat that operations on dual therapy that require extensive lysis of pleural adhesions may be associated with bleeding complications. However, there is no existing evidence on the safety of primary pleural surgery in patients receiving clopidogrel alone or in combination.

\section{Interventional radiology procedures and clopidogrel}

There are limited data on the safety of percutaneous procedures performed under radiological guidance in persons taking clopidogrel. While recommendations from the OR may be extrapolated to image-guided percutaneous procedures, the inability of the interventionalist to directly visualize and promptly control bleeding presents a unique risk (40). In 2012, the Society of Interventional Radiology 
(SIR) published consensus guidelines for periprocedural antiplatelet management according to the bleeding risk of each percutaneous image-guided intervention. All recommendations were based on the assumption of an elective interventional procedure and of a single hemostatic defect (41).

Procedures labeled as category 1 are considered to have a low-risk of bleeding, which would be easily detected and managed. These include drainage catheter exchange, thoracentesis, paracentesis, superficial abscess drainage, joint aspiration and injection, and superficial aspiration or biopsy. The recommendation is to withhold clopidogrel for $0-5$ days prior to such interventions and to continue aspirin therapy. Category 2 procedures are associated with a moderate risk of bleeding, and the recommendation is to continue aspirin and hold clopidogrel for 5 days. This category includes biopsies of the chest wall and lung as well as intra-abdominal and retroperitoneal abscess drainage or biopsy. Category 3 procedures, such as renal biopsy, pose the highest risk of bleeding, which would be difficult to identify and control. Both aspirin and clopidogrel should be held for 5 days prior to these procedures according to the SIR guidelines.

In the years since the SIR guidelines were issued, only two studies directly addressing APT management for percutaneous interventions by interventional radiologists have been published. One large retrospective study of image-guided percutaneous deep core needle biopsies found the overall incidence of major bleeding events to be low $(0.5 \%)(42)$. In the subset of 246 patients who were taking clopidogrel in proximity to the procedure, there was only one major bleeding event $(0.41 \%)$, which occurred in a patient within 7 days of clopidogrel ingestion. Limitations of this study include inconsistent data about the timing of last clopidogrel exposure and about aspirin co-administration. More informative is a recent study by Pieper et al. of 63 patients who had undergone various image-guided core needle biopsies. All subjects took clopidogrel within 5 days of the procedure with a mean abstinence time of 2.9 days prior to needle insertion. Twelve procedures were performed within 24 hours of clopidogrel ingestion. There were 48 patients $(76 \%)$ who also took aspirin within 5 days of the procedure (43). There was only one significant iatrogenic bleeding event $(1 / 63 ; 1.6 \%)$, which occurred after laceration of an intercostal artery during CT-guided pulmonary nodule biopsy.

Aggregating the encouraging, albeit limited, safety data on performing category 2 and 3 percutaneous needle procedures and even certain types of thoracic surgery in patients receiving clopidogrel, one might reasonably conclude that category 1 procedures, such as thoracentesis, should fare as well as, if not better than, these higher risk interventions. However, there is a paucity of direct evidence confirming the safety of clopidogrel use in category 1 percutaneous needle procedures. Fortunately, whatever data do exist come predominantly from studies of thoracentesis and chest tube insertion.

\section{Percutaneous pleural procedures and clopidogrel}

As mentioned, thoracentesis is categorized as a low-risk procedure for bleeding according to expert opinion and guidelines $(40,44)$. The bleeding concern relates primarily to iatrogenic hemothorax from injury of the intercostal artery, and less so bleeding from damage to a viscus, such as might occur if the spleen is inadvertently punctured. US guidance improves procedural accuracy in thoracentesis, so sub-diaphragmatic entry should be less of a concern in the US era (45). The ability of color Doppler US to identify intercostal vessels when selecting the safest site for thoracentesis has been demonstrated, but this step has not been universally adopted in clinical practice (46). When performed by experienced operators with standard US guidance, the overall hemothorax rate is exceedingly low. In their published experience with over 9,300 thoracentesis procedures, Ault et al. recorded only 5 hemothoraces, a rate of $0.05 \%$ (47). When large data sets from the Mayo Clinic were retrospectively analyzed, there were no hemothoraces even in patients who underwent thoracentesis with abnormal coagulation parameters, which casts doubt on the need for routine laboratory studies prior to this procedure $(48,49)$. Likewise, no hemothoraces occurred in 60 patients with thrombocytopenia $(<50 \mathrm{~K} / \mu \mathrm{L})$ or coagulopathy [international normalized ratio (INR) $>1.5$ ] subjected to thoracentesis as part of a prospective observational cohort at Yale-New Haven Hospital (50).

A separate body of literature exists on the safety of performing pleural drainage in patients receiving clopidogrel. For study purposes, thoracentesis and smallbore (i.e., $\leq 14$ French) chest tube placement are considered to be analogous. This is a reasonable assumption because small-bore chest tubes placed using the Seldinger technique have a comparably favorable safety profile to that of thoracentesis $(51,52)$. In fact, in some institutions, therapeutic thoracentesis may consist of the temporary 
Table 1 Summary of five available studies reporting bleeding rates associated with pleural drainage on clopidogrel

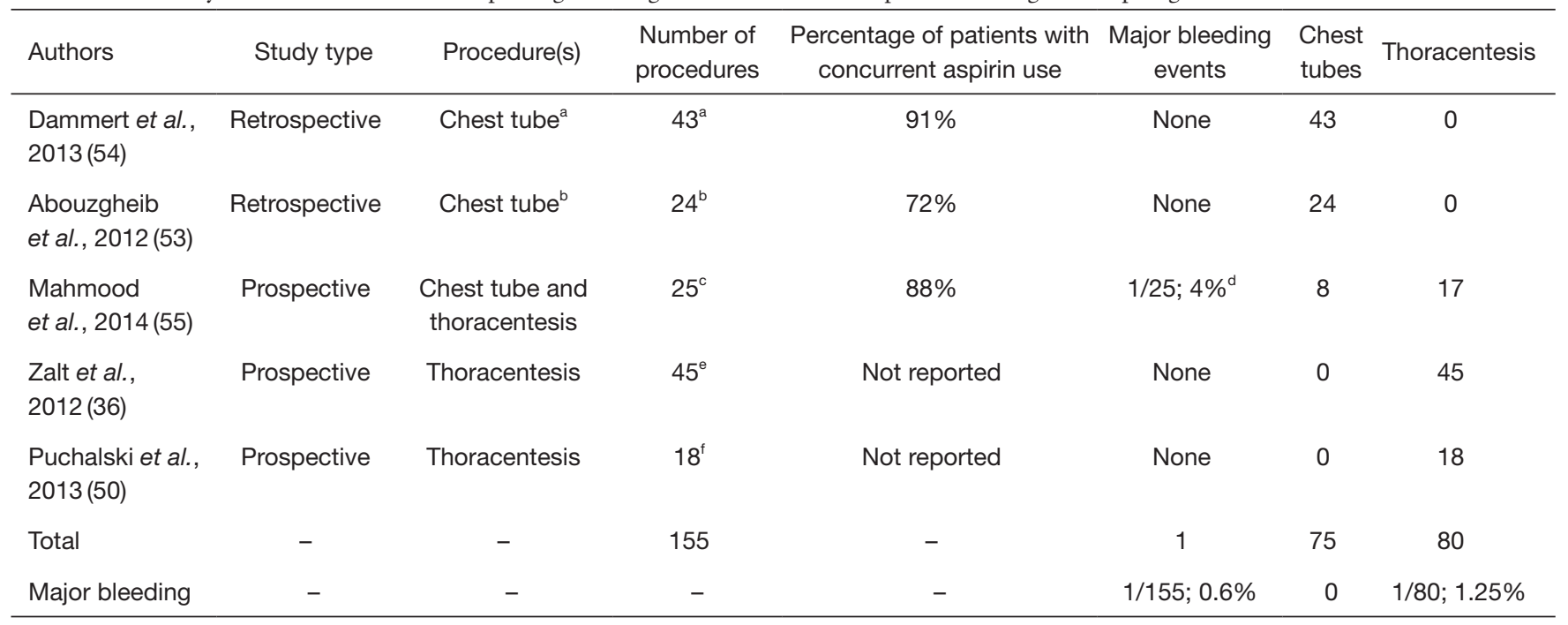

a, 43 procedures in 30 patients: $8 \mathrm{Fr}=11,14 \mathrm{Fr}=27,16 \mathrm{Fr}=5 ;{ }^{\mathrm{b}}, 24$ procedures in 18 patients: $8 \mathrm{Fr}=9,10 \mathrm{Fr}=1,12 \mathrm{Fr}=3,14 \mathrm{Fr}=1,16 \mathrm{Fr}$ $=10$; ${ }^{\mathrm{c}}, 25$ procedures in 25 patients: 17 thoracenteses and 8 chest tubes (all $14 \mathrm{Fr}$ ); ${ }^{\mathrm{d}}, 1$ patient with hemothorax after thoracentesis while on clopidogrel and aspirin; ${ }^{e}, 45$ procedures in 30 patients; ${ }^{f}, 18$ procedures in 18 patients.

insertion of a very small (e.g., eight French) pigtail catheter into the pleural space, in which case the two procedures are essentially indistinguishable. There are some practical differences, however, between the two procedures in the event of a hemothorax caused by the procedure itself. One is that an iatrogenic hemothorax should be apparent more quickly when the drainage catheter is left in place based on the appearance of the output. Another is that the placement of a drain is in itself the first step in the management of an iatrogenic hemothorax until it is determined whether a hemostatic intervention is required.

The retrospective data on pleural drainage and clopidogrel encompass a total of 54 patients across two studies who underwent 67 US-guided small-bore chest tube insertions $(53,54)$. No life-threatening bleeding was reported in any of these procedures. In the earliest prospective study, Zalt et al. performed 45 US-guided thoracentesis procedures in 30 patients on clopidogrel, and in their sample there was 1 instance of a superficial hematoma at the puncture site that did not lead to a significant drop in hemoglobin (36). Mahmood et al. prospectively enrolled 25 consecutive subjects who underwent thoracentesis or small-bore chest tube placement while taking clopidogrel and compared this group to 50 contemporaneous patients who likewise underwent pleural drainage but without clopidogrel (55). There was one hemothorax during the study, which occurred in the clopidogrel cohort, as indicated by a $1.6 \mathrm{gm} / \mathrm{dL}$ decrease in hemoglobin post-procedure in conjunction with increased pleural effusion on chest $X$-ray. The hemothorax was managed successfully with small-bore chest tube placement. Puchalski et al. conducted a prospective study of 312 thoracentesis patients, 130 of whom had an increased bleeding risk as defined by the investigators (50). Eighteen of the 130 patients (14\%) assigned to the increased risk group were being actively treated with clopidogrel; 8 of these 18 also had other predispositions to bleeding. No hemothoraces occurred in the entire study, and the change in hematocrit post procedure was not significantly different between those with and without a bleeding risk. Taken together, these small studies report one instance of hemothorax in a sample of 155 pleural procedures. This translates to a bleeding rate of $0.6 \%$, which is still higher than that in the study by Ault et al. quoted above in a general population undergoing thoracentesis but is comparable to, for example, conventional transbronchial biopsy in persons not taking antiplatelet agents and is certainly lower than that reported for bronchoscopic cryobiopsy $(56,57)$. Table 1 summarizes and aggregates the bleeding rates reported by the aforementioned studies.

\section{Conclusions}

At the present time, only observational data are available to 
guide conclusions about the safety of percutaneous pleural drainage in patients taking clopidogrel. In aggregate, the evidence allows one to conclude that urgent percutaneous pleural drainage using current techniques can be performed with an acceptable safety profile in patients treated with clopidogrel. Of course, if deemed feasible, a lower bleeding risk would be achieved if the drainage were delayed for at least 5 days while the clopidogrel is withheld. Concordant results of larger, collaborative, ideally prospective randomized studies, or at least big registry data, are needed to strengthen the level of confidence in such an approach to this challenging clinical scenario.

\section{Acknowledgements}

None.

\section{Footnote}

Conflicts of Interest: The authors have no conflicts of interest to declare.

\section{References}

1. Puchalski J. Thoracentesis and the risks for bleeding: a new era. Curr Opin Pulm Med 2014;20:377-84.

2. Becker RC, Sexton T, Smyth SS. Translational implications of platelets as vascular first responders. Circ Res 2018;122:506-22.

3. Eikelboom JW, Hirsch J, Spencer FA, et al. Antiplatelet drugs: Antithrombotic Therapy and Prevention of Thrombosis, 9th ed: American College of Chest Physicians Evidence-Based Clinical Practice Guidelines. Chest 2012;141:e89S-119S.

4. Verstraete $M$, Zoldheyi P. Novel antithrombotic drugs in development. Drugs 1995;49:856-84.

5. Davì G, Patrono C. Platelet activation and atherothrombosis. N Engl J Med 2007;357:2482-94.

6. Weitz JI, Hirsh J, Samama MM. New antithrombotic drugs. Chest 2008;133:234S-56S.

7. Anselmino M, Malmberg K, Ohrvik J, et al. Evidencebased medication and revascularization: powerful tools in the management of patients with diabetes and coronary artery disease: a report from the Euro Heart Survey on diabetes and the heart. Eur J Cardiovasc Prev Rehabil 2008;15:216-23.

8. Pereillo JM, Maftouh M, Andrieu A, et al. Structure and stereochemistry of the active metabolite of clopidogrel.
Drug Metab Dispos 2002;30:1288-95.

9. Savi P, Pereillo JM, Uzabiaga MF, et al. Identification and biological activity of the active metabolite of clopidogrel. Thromb Haemost 2000;84:891-6.

10. Hagihara K, Nishiya Y, Kurihara A, et al. Comparison of human cytochrome $\mathrm{P} 450$ inhibition by the thienopyridines prasugrel, clopidogrel, and ticlopidine. Drug Metab Pharmacokinet 2008;23:412-20.

11. Savi P, Herbert JM. Clopidogrel and ticlopidine: P2Y12 adenosine diphosphate-receptor antagonists for the prevention of atherothrombosis. Semin Thromb Hemost 2005;31:174-83.

12. Quinn MJ, Fitzgerald DJ. Ticlopidine and clopidogrel. Circulation 1999;100:1667-72.

13. Ferraris VA, Saha SP, Oesterich JH, et al. 2012 update to the Society of Thoracic Surgeons guideline on use of antiplatelet drugs in patients having cardiac and noncardiac operations. Ann Thorac Surg 2012;94:1761-81.

14. Wiviott SD, Braunwald E, McCabe CH, et al. Prasugrel versus clopidogrel in patients with acute coronary syndromes. N Engl J Med 2007;357:2001-15.

15. Brandt JT, Payne CD, Wiviott SD, et al. A comparison of prasugrel and clopidogrel loading doses on platelet function: magnitude of platelet inhibition is related to active metabolite formation. Am Heart J 2007;153: 66.e9-16.

16. Mega JL, Close SL, Wiviott SD, et al. Cytochrome P450 genetic polymorphisms and the response to prasugrel: relationship to pharmacokinetic, pharmacodynamic, and clinical outcomes. Circulation 2009;119:2553-60.

17. Cerfolio RJ, Minnich DJ, Bryant AS. General thoracic surgery is safe in patients taking clopidogrel (Plavix). J Thorac Cardiovasc Surg 2010;140:970-6.

18. Herbert JM, Frehel D, Vallée E, et al. Clopidogrel, a novel antiplatelet and antithrombotic agent. Cardiovasc Drug Rev 1993;11:180-98.

19. CAPRIE Steering Committee. A randomised, blinded, trial of clopidogrel versus aspirin in patients at risk of ischaemic events (CAPRIE). Lancet 1996;348:1329-39.

20. Yusuf S, Zhao F, Mehta SR, et al. Effects of clopidogrel in addition to aspirin in patients with acute coronary syndromes without ST-segment elevation. N Engl J Med 2001;345:494-502.

21. Steinhubl SR, Berger PB, Mann JT, et al. CREDO Investigators. Early and sustained dual oral antiplatelet therapy following percutaneous coronary intervention: a randomized controlled trial. JAMA 2002;288:2411-20.

22. Chen ZM, Jiang LX, Chen YP, et al. COMMIT 
(Clopidogrel and Metoprolol in Myocardial Infarction

Trial) collaborative group. Addition of clopidogrel to aspirin in 45,852 patients with acute myocardial infarction: randomised placebo-controlled trial. Lancet 2005;366:1607-21.

23. Sabatine MS, Cannon CP, Gibson CM, et al. CLARITYTIMI 28 Investigators. Addition of clopidogrel to aspirin and fibrinolytic therapy for myocardial infarction with STsegment elevation. N Engl J Med 2005;352:1179-89.

24. Wallentin L, Becker RC, Budaj A, et al. Ticagrelor versus clopidogrel in patients with acute coronary syndromes. $\mathrm{N}$ Engl J Med 2009;361:1045-57.

25. Kandan SR, Johnson TW. Contemporary Antiplatelet Strategies in the Treatment of STEMI using Primary Percutaneous Coronary Intervention. Interv Cardiol 2015;10:26-31.

26. Korte W, Cattaneo M, Chassot PG, et al. Peri-operative management of antiplatelet therapy in patients with coronary artery disease: joint position paper by members of the Working Group on Perioperative Haemostasis of the Society on Thrombosis and Haemostasis Research (GTH), the Working Group on Perioperative Coagulation of the Austrian Society for Anesthesiology, Resuscitation and Intensive Care (OGARI), and the Working Group on Thrombosis of the European Society for Cardiology (ESC). Thromb Haemost 2011;105:743-9.

27. Chapman TW, Bowley DM, Lambert AW, et al. Haemorrhage associated with combined clopidogrel and aspirin therapy. Eur J Vasc Endovasc Surg 2001;22:478-9.

28. Algra A, van Gijn J. Is clopidogrel superior to aspirin in secondary prevention of vascular disease? Curr Control Trials Cardiovasc Med 2000;1:143-5.

29. Iakovou I, Schmidt T, Bonizzoni E, et al. Incidence, predictors, and outcome of thrombosis after successful implantation of drug eluting stent. JAMA 2005;293:2126-30.

30. Alshawabkeh LI, Banerjee S, Brilakis ES. Systematic review of the frequency and outcomes of non-cardiac surgery after drug-eluting stent implantation. Hellenic J Cardiol 2011;52:141-8.

31. Machecourt J, Danchin N, Lablanche JM, et al. on behalf of EVASTENT Investigators. Risk factors for stent thrombosis after implantation of sirolimuseluting stents in diabetic and nondiabetic patients: the EVASTENT Matched-Cohort Registry. J Am Coll Cardiol 2007;50:501-8.

32. Moreno R, Fernandez C, Hernandez R, et al. Drug-eluting stent thrombosis: results from a pooled analysis including
10 randomized studies. J Am Coll Cardiol 2005;45:954-9.

33. Kuchulakanti PK, Chu WW, Torguson R, et al. Correlates and long- term outcomes of angiographically proven stent thrombosis with sirolimus-and paclitaxel-eluting stents. Circulation 2006;113:1108-13.

34. van Werkum JW, Heestermans AA, Zomer AC, et al. Predictors of coronary stent thrombosis: the Dutch stent thrombosis registry. J Am Coll Cardiol 2009;53:1399-409.

35. D'Ascenzo F, Colombo F, Gaita F, et al. Discontinuation of dual antiplatelet therapy over 12 months after acute coronary syndromes increases risk for adverse events in patients treated with percutaneous coronary intervention: systematic review and meta-analysis. J Interv Cardiol 2014;27:233-41.

36. Zalt MB, Bechara RI, Parks C, et al. Effect of routine clopidogrel use on bleeding complications after ultrasound-guided thoracentesis. J Bronchology Interv Pulmonol 2012;19:284-7.

37. Albaladejo P, Marret E, Samama CM, et al. Non-cardiac surgery in patients with coronary stents: the RECO study. Heart 2011;97:1566-72.

38. Ceppa DP, Welsby IJ, Wang TY, et al. Perioperative management of patients on clopidogrel (Plavix) undergoing major lung resection. Ann Thorac Surg 2011;92:1971-6.

39. Yu WS, Jung HS, Lee JG, et al. Safety of thoracoscopic surgery for lung cancer without interruption of antiplatelet agents. J Thorac Dis 2015;7:2024-32.

40. Patel IJ, Davidson JC, Nikolic B, et al. Consensus guidelines for periprocedural management of coagulation status and hemostasis risk in percutaneous image-guided interventions. J Vasc Interv Radiol 2012;23:727-36.

41. Patel IJ, Davidson JC, Nikolic B, et al. Addendum of newer anti-coagulants to the SIR consensus guideline. J Vasc Interv Radiol 2013;24:641-5.

42. Atwell TD, Smith RL, Hesley GK, et al. Incidence of bleeding after 15,181 percutaneous biopsies and the role of aspirin. AJR Am J Roentgenol 2010;194:784-9.

43. Pieper M, Schmitz J, McBane R, et al. Bleeding complications following image-guided percutaneous biopsies in patients taking clopidogrel—a retrospective review. J Vasc Interv Radiol 2017;28:88-93.

44. Baron TH, Kamath PS, McBane RD. Management of antithrombotic therapy in patients undergoing invasive procedures. N Engl J Med 2013;368:2113-24.

45. Diacon AH, Brutsche MH, Solér M. Accuracy of pleural puncture sites: a prospective comparison of clinical examination with ultrasound. Chest 2003;123:436-41.

46. Salamonsen M, Ellis S, Paul E, et al. Thoracic ultrasound 
demonstrates variable location of the intercostal artery.

Respiration 2012;83:323-9.

47. Ault MJ, Rosen BT, Scher J, et al. Thoracentesis outcomes: a 12-year experience. Thorax 2015;70:127-32.

48. Patel MD, Joshi SD. Abnormal preprocedural international normalized ratio and platelet counts are not associated with increased bleeding complications after ultrasound-guided thoracentesis. AJR Am J Roentgenol 2011;197:W164-8.

49. Hibbert RM, Atwell TD, Lekah A, et al. Safety of ultrasound-guided thoracentesis in patients with abnormal preprocedural coagulation parameters. Chest 2013;144:456-63.

50. Puchalski JT, Argento AC, Murphy TE, et al. The safety of thoracentesis in patients with uncorrected bleeding risk. Ann Am Thorac Soc 2013;10:336-41.

51. Horsley A, Jones L, White J, et al. Efficacy and complications of small-bore, wire-guided chest drains. Chest 2006;130:1857-63.

52. Davies HE, Merchant S, McGown A. A study of

Cite this article as: Linder K, Epelbaum O. Percutaneous pleural drainage in patients taking clopidogrel: real danger or phantom fear? J Thorac Dis 2018;10(8):5162-5169. doi: 10.21037/jtd.2018.04.161 complications of small bore "Seldinger" intercostal chest drains. Respirology 2008;13:603-7.

53. Abouzgheib W, Shweihat YR, Meena N, et al. Is chest tube insertion with ultrasound guidance safe in patients using clopidogrel? Respirology 2012;17:1222-4.

54. Dammert P, Pratter M, Boujaoude Z. Safety of ultrasound-guided small-bore chest tube insertion in patients on clopidogrel. J Bronchology Interv Pulmonol 2013;20:16-20.

55. Mahmood K, Shofer SL, Moser BK, et al. Hemorrhagic complications of thoracentesis and small-bore chest tube placement in patients taking clopidogrel. Ann Am Thorac Soc 2014;11:73-9.

56. Herth FJ, Becker HD, Ernst A. Aspirin does not increase bleeding complications after transbronchial biopsy. Chest 2002;122:1461-4.

57. Lentz RJ, Argento AC, Colby TV, et al. Transbronchial cryobiopsy for diffuse parenchymal lung disease: a state-ofthe-art review of procedural techniques, current evidence, and future challenges. J Thorac Dis 2017;9:2186-203. 